HARRAN ÜNIVERSITESI

MÜHENDISLIK DERGisi

HARRAN UNIVERSITY JOURNAL OF ENGINEERING

e-ISSN: 2528-8733

\section{HARRAN ÜNIVERSITESİ MÜHENDİSLİK DERGISII}

HARRAN UNIVERSITY JOURNAL of ENGINEERING

e-ISSN: 2528-8733 (ONLINE)

URL: http://dergipark.gov.tr/humder

Şanlıurfa İstasyonunun Aylık Ortalama Güneşlenme Şiddetinin Farklı Yöntemler ile Trend Analizi

Trend Analysis of Monthly Average Solar Radiation of Şanlıurfa Station with Different Methods

Yazar(lar) (Author(s)): Veysel GÜMÜŞ'1, Oğuz ŞIMŞEK²

1 ORCID ID: 0000-0003-2321-9526

2 ORCID ID: 0000-0001-6324-0229

Bu makaleye şu şekilde atıfta bulunabilirsiniz (To cite to this article): Gümüş V., Şimşek O., "Şanlıurfa İstasyonunun Aylık Ortalama Güneşlenme Şiddetinin Farklı Yöntemler ile Trend Analizi", Harran Üniversitesi Mühendislik Dergisi, 5(3): 227-238, (2020).

Erişim linki (To link to this article): http://dergipark.gov.tr/humder/archive 


Mühendislik Dergisi

\title{
Şanlıurfa İstasyonunun Aylık Ortalama Güneşlenme Şiddetinin Farklı Yöntemler ile Trend Analizi
}

\author{
Veysel GÜMÜŞ ${ }^{1}$ Oğuz Şi̇MŞEK ${ }^{1, *}$ \\ ${ }^{1}$ Harran Üniversitesi, Mühendislik Fakültesi, İnşaat Mühendisliği Bölümü, 63050, Haliliye/Şanlıurfa
}

$\ddot{O} \mathbf{z}$

\section{$\underline{\text { Makale Bilgisi }}$ \\ Bassvuru: $19 / 11 / 2020$ \\ Yayın: 25/12/2020}

\section{Anahtar Kelimeler}

\section{Trend analizi}

Mann-Kendall testi

Yenilikçi Şen Yöntemi

Güneşlenme şiddeti

Sanliurfa istasyonu

\section{Keywords}

Trend analysis Mann-Kendall test Innovative Şen Method Solar radiation Şanlıurfa station
Güneşlenme şiddeti, çeşitli fiziksel, kimyasal ve biyolojik süreçlerin enerji dengelerinde önemli bir rol oynar. Güneş enerjisinin ana parametresi olan güneşlenme şiddetinin miktarındaki değişimler, hidrolojik döngüyü, ekosistemi ve iklimin değişimini büyük ölçüde etkiler. Bunun yanında güneş enerjisi, fosil yakıtlar gibi geleneksel kaynaklardan çok daha düşük bir çevre kirliliğine sahiptir. Dünyanın dört bir yanındaki tüm yenilenebilir ve sürdürülebilir enerji kaynaklarının en bol olanı güneş enerjisidir ve ticari olarak da çok geniş çapta kullanılmaktadır. $\mathrm{Bu}$ nedenden dolayı, güneşlenme şiddetinin zamansal ve mekânsal değişimlerinin doğru belirlenmesi ve anlaşılması, meteorolojik ve hidrolojik süreçler, tarımsal ve endüstriyel üretimle birlikte güneşten enerji üretimi açısından büyük önem taşımaktadır. Bu çalışmada, Şanlıurfa istasyonuna ait, 1982-2010 yılları arasındaki yıllık ve aylık ortalama güneşlenme şiddeti değerlerinin trendleri, parametrik olmayan Mann-Kendall ve Spearman'in Rho testleri ile ayrıca, sonuçları grafiksel olarak verme yeteneğine sahip Yenilikçi Şen Yöntemi ile yapılmıştır. Trend eğimleri ise Sen'in Trend Eğim Metodu ile hesaplanmıştır. İç bağımlılık etkilerinden arındırılmış zaman serilerinin trend analizi sonucunda, Mann-Kendall ve Spearman'ın Rho testlerinde sadece mart ve ekim aylarında anlamlı artan yönde trend belirlenmiştir. Ancak, Şen'in trend testi ile yapılan analizlerde ise aylık ve yıllık güneşlenme şiddeti değerlerinde anlamlı artan yönde trend belirlenmiştir. Sen'in trend eğim metoduna göre en fazla artış yıllık $3.21 \mathrm{cal} / \mathrm{cm}^{2}$ ile mayıs ayında, en az artış ise yıllık $0.44 \mathrm{cal} / \mathrm{cm}^{2}$ ile şubat ayında gerçekleştiği görülmüştür.

\section{Trend Analysis of Monthly Average Solar Radiation of Şanlıurfa Station with Different Methods}

\begin{abstract}
The solar radiation crucially affects the energy balances of various physical, chemical and biological processes. The variation in the amount of solar radiation $(\mathrm{cal} / \mathrm{cm} 2)$ that is the main parameter of solar energy to a large extend influences the hydrological cycle, ecosystem and climate changes. In addition, solar energy consumption conduces toward much lower environmental pollution compared to that of traditional sources such as fossil fuels. Solar energy that is the most abundant of all renewable and sustainable energy sources around the world is widely used commercially. Accordingly, the most prominent issues are to identify and engage evidently the temporal and spatial variations of solar radiation, the meteorological and hydrological processes, the agricultural and industrial productions, and the solar energy production. In this context, the presented study identifies the annual and monthly averaged sun exposure intensity values for Şanlıurfa station for the period of 1982-2010 by using nonparametric Mann-Kendall and Spearman's Rho tests, and also made with the Innovative Şen Method which has the ability to give results graphically. The trend slopes were specified employing Sen's trend slope method. As a result of the trend analysis study that is taken into consideration the serial correlation, Mann-Kendall and Spearman's Rho tests provide a significant trend only in March and October periods. Whereas the trend analysis using Şen's trend test reveals that the trends significantly increase regarding the monthly and annual sunlight intensity values. Considering the trend slope method, the maximum increase is obtained from the period of May having the value of $3.21 \mathrm{cal} / \mathrm{cm}^{2}$ per year, and the minimum increase is for February with the value of $0.44 \mathrm{cal} / \mathrm{cm}^{2}$ per year.
\end{abstract}




\section{GİRIŞ (INTRODUCTION)}

Dünya'nın enerji kaynăğ güneşten yayılan 1şınlardır. Güneş 1şınları hemen hemen tüm canlıların yaşamlarını devam etmek için kullandığı oksijenin bitkiler tarafından üretildiği fotosentez olayının en önemli faktörüdür. Güneş 1şınları sadece fotosentez olayında değil, tarımsal verimlilik, hidrolojik döngü, ekolojik ekosistemin dengesi ve iklim gibi birçok farklı alan üzerinde etkin rol oynamaktadır [1-3]. Güneş 1şınlarında meydana gelen herhangi bir değişiklik canlılar, doğa ve çevremiz üzerinde oldukça büyük ve olumsuz etkiler doğurabilmektedir.

Son yıllarda yapılan bilimsel araştırmalarda, dünyada güneşlenme şiddetinin bazı bölgelerde düşüş, bazı bölgelerde ise artış trendinde olduğu gözlenmiştir [4-7]. Değişik bölgelerde farklı özellik (artış-azalış) gösteren güneşlenme şiddetinin, yersel ve zamansal değişiminin doğru belirlenmesi oldukça zordur. Güneşlenme şiddetinin yersel ve zamansal değişiminin doğru belirlenmesi ve net bir şekilde anlaşılması, meteorolojik ve hidrolojik süreçleri, ekolojik değişimleri, enerji gelişimini ve kullanımının en iyi şekilde yönetilmesi ve bu kaynakların daha verimli kullanılmasını mümkün kılmaya yardımcı olacaktır. Hidrolojik ve meteorolojik zaman serilerinin trendlerinin belirlenmesinde Mann-Kendall testi, $t$ testi, $f$ testi ve Spearman's Rho testi gibi farklı yöntemler birçok araştırmacı tarafından kullanılmıştır. Bu yöntemlerin kullanıldığı çalışmaların sonuçları incelendiğinde yöntemlerin uygulanan bölgelerdeki hidro-meteorolojik verilerin eğilimlerinin yani trendlerinin belirlenmesinde oldukça başarılı olduğu görülmektedir. Dünya genelinde yapılan çalışmalar incelendiğinde, Caloiero ve ark. [8] tarafından İtalyanın Calabria kentine ait yıllık ve mevsimsel yağışların trendleri belirlemişlerdir. Trendleri belirlemek için analizlerde MannKendall testini kullanmışlardır. Çalışma sonucunda, yıllık ve sonbahar-kış mevsiminde meydana gelen yağışlarda düşüş trendi görülürken, yaz mevsimin de meydana gelen yağışlar da ise artış trendinin olduğu belirtilmiştir. Maroon Nehri üzerinde dört farklı istasyona ait 1989-2008 yılları arasındaki mevsimsel ve yıllık su kalitesi parametrelerinin trendleri Tabari ve ark. [9] tarafından incelenmiştir. Bazı istasyonlarda kalsiyum, magnezyum, sodyum emilim oranında önemli trend varlığı görülürken, bazı istasyonlarda ise $\mathrm{pH}$ ve bulanıklık değerlerinde anlamlı trend görüldüğü belirtilmiştir. Chowdhury ve ark. [10], Güney Avustralya'ya ait 100 yıldan fazla yağış verilerinin trendini Mann-Kendall testi, doğrusal regresyon ve Spearman's Rho testlerini kullanarak analiz etmişlerdir. Yapılan analiz sonucunda, Güney Avustralya'nın güney ve güneydoğu kesimlerinde azalan yönde trend varlığı belirlenmiştir. Ayrıca, ilkbahar ve yaz aylarındaki yağışlarda genel olarak artan trend görülürken, bunun aksine sonbahar ve kış aylarında yağış değerlerinde azalan trend tespit edilmiştir. Eriş ve Ağıralioğlu [11], Doğu Karadeniz Bölgesi'nin uzun süreli y1llık yağış ve akarsu serilerinin homojenliği, çift kütle eğrisi yöntemi ile kontrol edilmiş ve trendler MannKendall testi ile belirlenmişlerdir. Çalışmalarında, Doğu Karadeniz Bölgesi’nde bulunan 38 yağış ölçüm istasyonu ve 40 akış ölçüm istasyonuna ait kayıtlar kullanılmıştır. Çalışma sonucunda, ele alınan yağış gözlem istasyonlarından 38'inden 27'sinin homojen olduğu ve yağış verilerinde herhangi bir trend olmadığı belirlenirken, diğer dokuz istasyonunun homojen olmadığ 1 ve sadece bu istasyonlardan dört tanesinde elde edilen yağış verilerinde trend olduğu görülmüştür. Yıllık akış verileri için 40 istasyondan 22'sinin homojen olduğu ve herhangi bir trendin olmadığ bulunmuştur. Yenigün ve ark. [12], Firat havzasında 22 akım gözlem istasyonunda elde edilen yıllık ortalama, minimum ve maksimum akış değerlerinin trend analizini Mann - Kendall ve Spearman'ın Rho testlerini kullanarak yapmışlardır. Akış değerlerinde trend başlangıç yıllarının belirlenmesi için Mann-Kendal sıra korelasyon testini, doğrusal eğimlerini belirlemek için ise Sen'in trend eğim metodu kullanılmıştır. Trend analizi sonucunda, altı istasyonda yıllık minimum akışta anlamlı bir azalma trendi tespit edilirken ve yalnızca bir istasyon için artan yönde anlamlı trend varlı̆̆ görülmüştür. Yıllık maksimum akım değerlerinde herhangi bir istasyonda anlamlı bir trend görülmezken, sadece bir istasyonda yıllık ortalama akım değerleri için azalan yönde anlamlı trend belirlenmiştir. Gümüş [13], Seyhan ve Ceyhan Havzalarında elde edilmiş yağış ve sıcaklık değerlerinin mekânsal-zamansal trend analizini Mann-Kendall yöntemini kullanarak gerçekleştirmiştir. Elde edilen sonuçlardan, bu havzalar için yıllık maksimum sıcaklık değerlerine göre istatistiksel olarak anlamlı artma trend olduğunu ve trend başlangıç yıllarının 1990'lı ve 2000'li yılların ortası olduğu bildirilmiştir.

Literatürde farklı çalışmalarda farklı istatistiksel yöntemler kullanılarak başarılı sonuçlar elde edilmesine karşı1ık, bu istatiksel yöntemlerin bazı dezavantajları vardır. Örneğin, doğrusal regresyon, verilerin bağımsız ve normal olarak dağıtılmasını gerektirirken, bu da meteorolojik ve hidrolojik zaman serileri (genellikle çarpık veriler); Mann-Kendall ve Spearman's Rho testi, trendin tekdüze ve normal dağılım olarak varsayılabileceği durumlar için uygundur [14,15], bu nedenle meteorolojik ve hidrolojik zaman 
serileri için varyasyon trendlerini tespit etmek için bu geleneksel yöntemleri uygulamanın bazı olumsuz yönleri vardır. Bu yöntemlerin yanında son yıllarda farklı araştırmacılar tarafından oldukça sık kullanılan Şen [14] tarafından geliştirilen Yenilikçi Şen Yöntemi'ni farklı zaman serilerine uygulanmıştır. Kisi [16], altı farklı istasyonda ölçülmüş aylık tava buharlaşma değerlerinin trendlerini Mann-Kendall, Spreaman Rho testi ve Yenilikçi Şen Yöntemlerini kullanarak belirlemiştir. Ele alınan üç istasyonda kullanılan yöntemlerin birbirine benzer sonuçlar verdiği görülmüştür. Bazı istasyonlarda, Mann-Kendall ve Spreaman Rho testleri kullanılarak anlamlı bir trend varlığı belirlenemezken, düşük, orta ve yüksek tava buharlaşması değerlerinde Şen metoduyla azalan veya artan yönde trend belirlendiği belirtilmiştir. Wu ve Qian [17], Çin'in Shaanxi Eyaletindeki 14 istasyonda yıllık ve mevsimsel yağış değişim trendleri Yenilikçi Şen Yöntemini kullanarak analiz etmek için bir algoritma önermişlerdir. Literatürde bulunan çok az çalışmada, dünyadaki farklı bölgelerin güneşlenme şiddetinin trendi belirlenmeye çalışılmıştır. Liu ve ark. [18], Haihe Nehri havzasında altı istasyona ait 1957-2008 yılları arasında güneşlenme şiddetinin trendlerini Mann Kendall testini kullanarak analiz etmişlerdir. Çalışma sonucunda, ele alınan tüm istasyonlarda güneşlenme şiddetinde azalış trendi görülmüştür. Aksoy [19], Türkiye'de 20 farklı istasyonda elde edilen yıllık global güneşlenme şiddetinin trendini Mann-Kendall testi ile belirlemiştir. 20 farklı istasyona ait veriyi 85 ağa bölerek analizlerini gerçekleştirmiştir. Yapılan analiz sonucunda, zaman serilerinin ortalama\%3 varyasyona sahip olduğu ve 62 ağ hücresinde istatistiksel olarak anlamlı bir artı̧̧ trendi sergilediği görülmüştür. Ayrıca, zaman serilerinin 1990 yıllının ortalarında anlamlı trend başlangıcını olduğu tespit edilmiştir. Zhou ve ark. [20], Çin'in 5 farklı bölgesinde bulunan 48 istasyonda 1962-2015 y1lları arasında elde edilen yıllık ve mevsimsel güneşlenme şiddeti değerlerinin trendini Yenilikçi Şen Yöntemi ile analiz etmişlerdir. Çalışma sonucunda, güneşlenme şiddeti değerlerinin çoğu istasyonda azalma trendi görülürken, bazı istasyonlar ılıman muson ikliminin yaşandığı Çin'in doğu kesiminde önemli derece artma trendi olduğu görülmüştür. Ayrıca, Yenilikçi Şen Yöntemi kullanılarak elde edilen trend analizi sonuçları, doğrusal regresyon analizi ve Mann-Kendall testiyle elde edilen trendler ile karşılaştırılmıştır. Karşılaştırma sonucunda doğrusal regresyon analizi ve Mann-Kendall testiyle tespit edilebilen trendlerin Yenilikçi Şen Yöntemiyle benzerlik gösterdiği belirtilmiştir. Doğrusal regresyon analizi ve Mann-Kendall testiyle etkili bir şekilde tespit edilemeyen birçok trend (93 zaman serisi), Yenilikçi Şen Yöntemi kullanılarak tanımlanabilmiştir. Sonuç olarak Yenilikçi Şen Yönteminin, geleneksel doğrusal regresyon analizi ve Mann-Kendall kullanılarak gözlemlenemeyen trendleri tespit edebildiği için bu yöntemlerden üstün olduğu belirlenmiştir.

Literatürde bulunan çalışmalar dikkate alındığında, Türkiye'de güneşlenme şiddetinin trendinin belirlenmesi konularında çalışmaların kısıtlı olduğu ve özellikle güneşlenme süresinin oldukça fazla olduğu Güneydoğu Anadolu bölgesinde detaylı bir çalışma bulunmadığı görülmektedir. Bu çalışmada, Türkiye’nin Güneydoğu Anadolu Bölgesi'nde bulunan Şanlıurfa istasyonuna ait güneşlenme şiddetini değerlerinin trend analizi Yenilikçi Şen Yöntemi, Mann-Kendall testi ve Spermann Rho testi kullanılarak gerçekleştirilmiştir. Üç farklı yöntemin güneşlenme şiddetinin trendini belirlemedeki başarısı test edilmiş ve yöntemler değerlendirilmiştir.

\section{MATERTAL VE YÖNTEM (MATERIAL AND METHOD)}

\section{1 Çalışma Alanı (Study Area)}

Yenilenebilir ve temiz bir enerji kaynağı olan güneş enerjisinin üretimi için güneşlenme şiddeti en önemli parametrelerden biridir. Bu çalışma kapsamında güneşlenme şiddetinin trendinin belirlenmesi için Türkiye'nin Güneydoğusunda yer alan Şanlıurfa istasyonunun (370 $09^{\prime} 38,9^{\prime \prime}$ N, 38 $47^{\circ} 10,7^{\prime \prime}$ E) 19822010 yılları arasında ölçülen verileri kullanılmıştır. Şanlıurfa, Türkiye'nin en önemli kalkınma projelerinden biri olan Güneydoğu Anadolu Projesi (GAP) bölgesinde yer almaktadır. Bu proje ile verimli tarım arazilerinin sulanması mümkün olmuştur. GAP bölgesinin önemli bir kısmında su kendi enerjisi ile ve çoğunlukla açık kanaletler üzerinden tarım arazilerine ulaştırılmaktadır. Bölge özelinde, tarım arazilerinde sulamanın yapılması için kullanılan enerjinin güneş enerjisinden sağlanabilmesinin verimliliği açısından da güneşlenme şiddetinin trendinin bilinmesi yararlı olacaktır. Şekil 1'de Yenilenebilir Enerji Genel Müdürlüğü bünyesinde hazırlanan Güneş Enerjisi Potansiyeli Atlası (GEPA)'nın Türkiye ve Şanlıurfa özelinde güneşlenme şiddetinin mekânsal dağılımı verilmiştir [21]. Ayrıca, Tablo 1'de tüm Türkiye'nin ve Şanlıurfa istasyonun güneşlenme şiddetlerinin aylık dağılımları görülmektedir. Bu iki veri 1şığında Şanlıurfa'da yıllık toplam güneşlenme şiddetinin $135 \mathrm{cal} / \mathrm{cm}^{2}\left(1580 \mathrm{kWh} / \mathrm{m}^{2}\right)$ olduğu ve bu değerin 
Türkiye'nin ortalama değerinden [21] yaklaşık olarak \%26,5 fazla olduğu görülmektedir. Ayrıca Tablo 1'e göre, en yüksek ortalama güneşlenme şiddeti değeri haziran ayında, en düşük güneşlenme şiddeti değeri ise aralık ayında olduğu görülmektedir.

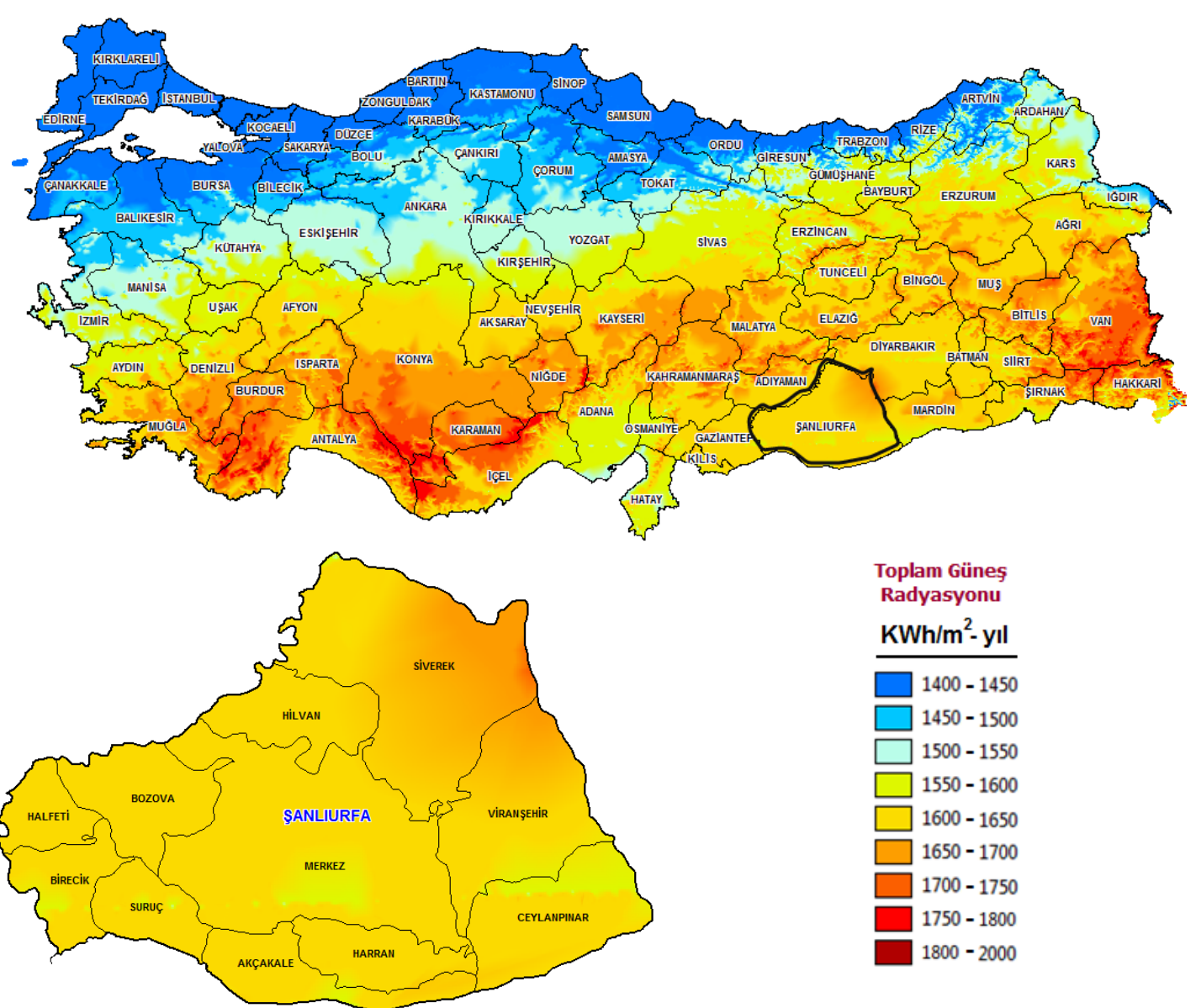

Şekil 1. Türkiye ve Şanlıurfa iline ait güneşlenme şiddetinin mekânsal dăğllımı [21]

Tablo 1. Şanlıurfa istasyonuna ait güneşlenme şiddetine ait istatistikler

\begin{tabular}{|c|c|c|c|c|c|c|c|}
\hline$A y$ & $\begin{array}{c}\text { Ortalama } \\
\left(\mathrm{cal} / \mathrm{cm}^{2} / \text { gün }\right)\end{array}$ & $\begin{array}{c}\text { Mak. } \\
\left(\mathrm{cal} / \mathrm{cm}^{2} / g \ddot{u} n\right)\end{array}$ & $\begin{array}{c}\text { Min. } \\
\left(\mathrm{cal} / \mathrm{cm}^{2} / g \ddot{\text { Inn }}\right)\end{array}$ & $\begin{array}{l}\text { Standart } \\
\text { Sapma }\end{array}$ & Çarpıklık & $\begin{array}{c}\text { Șanlıurfa GSS } \\
\left(\mathrm{cal} / \mathrm{cm}^{2} / \mathrm{ay}\right)\end{array}$ & $\begin{array}{l}\text { Türkiye'nin } \\
\text { Ortalama GS }\left(\text { cal/cm }^{2} / \text { ay) }\right.\end{array}$ \\
\hline OCAK & 175,2 & 242,6 & 123,5 & 32,7 & 0,24 & 5430 & 4450 \\
\hline ŞUBAT & 249,4 & 326,0 & 170,7 & 37,6 & 0,15 & 6983 & 5440 \\
\hline MART & 360,0 & 448,7 & 261,3 & 43,3 & $-0,61$ & 11161 & 8310 \\
\hline NISAN & 452,4 & 524,3 & 370,0 & 43,4 & $-0,34$ & 13572 & 10510 \\
\hline MAYIS & 543,1 & 633,3 & 440,2 & 52,3 & $-0,39$ & 16836 & 13230 \\
\hline HAZIRAN & 613,7 & 696,0 & 522,6 & 49,9 & $-0,59$ & 18411 & 14510 \\
\hline TEMMUZ & 596,1 & 668,6 & 501,5 & 44,6 & $-0,70$ & 18478 & 15080 \\
\hline Ă̈USTOS & 535,4 & 597,4 & 462,2 & 40,7 & $-0,54$ & 16599 & 13620 \\
\hline$E Y L \ddot{U} L$ & 452,4 & 501,2 & 393,9 & 32,0 & $-0,61$ & 13573 & 10600 \\
\hline EKIM & 329,3 & 397,9 & 282,3 & 28,7 & 0,38 & 10208 & 7730 \\
\hline KASIM & 219,3 & 264,8 & 150,0 & 28,1 & $-0,88$ & 6580 & 5230 \\
\hline ARALIK & 155,6 & 206,3 & 108,1 & 26,2 & 0,28 & 4823 & 4030 \\
\hline
\end{tabular}

\subsection{Yöntem (Method)}

Hidro-meteorolojik bir zaman serisinde anlamlı bir azalma veya artma trendinin araştırılması için özel yöntemlerin kullanılması gerekmektedir [22]. Bu yöntemler ise parametrik olmayan yani veri setinin herhangi bir dağılıma uyma zorunluluğu olmayan yöntemlerden tercih edilmesi gerekmektedir. Literatürde farklı hidro-meteorolojik verilerin monotonik trendlerinin belirlenmesi için Mann-Kendall yöntemi sıklıkla 
kullanılmaktadır. Ancak parametrik olmayan bu yöntemlerde ortaya çıkan en önemli problem ise iç bağımlılık etkisinin olmasıdır. Bu nedenle veri setinin monotonik trendinin belirlenmesi öncesinde iç bağımlılık etkisinin giderilmesi gerekmektedir. Bunun için, Von Storch ve Navarra [23] iç bağımlılığın zaman serisi üzerinden etkisini kaldırmak için "pre-whitening" yöntemini önermektedir. Bu nedenle, çalışma kapsamında ilk olarak zaman serisinin iç bağımlılık etkisinin belirlenmesi gerekmektedir. Bunun için $\mathrm{x}_{1}, \mathrm{x}_{2}, \ldots \ldots \ldots, \mathrm{x}_{\mathrm{n}}$ örnek datası için Salas [24] tarafından önerilen ve Lag -1 yani zaman serisinin bir gecikmeli korelasyon katsayısının Denklem 1'de verilen aralıkta olup olmadığı kontrol edilir [13, 25, 26].

$$
\frac{-1-1,645 \sqrt{n}-2}{n-1} \leq r_{1} \leq \frac{-1+1,645 \sqrt{n}-2}{n-1}
$$

$\mathrm{r}_{1}$ değerinin Denklem 1'deki aralıkta olması durumunda zaman serisinde iç bağımlılık olmadığı, aralığın dışında olması durumunda ise iç bağımlılık olduğu sonucuna varılır. İç bağımlılık olmaması durumunda zaman serisinde herhangi bir değişiklik yapılmadan test yapılır. Ancak iç bağımlılık olması durumunda $\left(x_{2}-r_{1} x_{1}, x_{3}-r_{1} x_{2}, \ldots \ldots \ldots \ldots \ldots \ldots, x_{n}-r_{l} x_{n}-1\right)$ işlemi uygulanarak "pre-whitened" zaman serisi elde edilerek trend analizi işlemi yapılır [26].

\subsubsection{Mann-Kendall Yöntemi (Mann-Kendall Method)}

Mann [27] ve Kendall [28] tarafindan önerilen bu test hidro-meteorolojik verilerde istatistiksel olarak anlamlı trend belirlemek için sıklıkla kullanılan parametrik olmayan bir testtir. Bu test ile bir zaman serisinde trend olup olmadığ $;$; "H $\mathrm{H}_{0}$ : trend yok" (sıfır hipotezi) ile kontrol edilmektedir [12]. Buna göre, test istatistiği S ve işaret fonksiyonu Denklem 2 ve 3'te verildiği gibi hesaplanır. Daha sonra Denklem 4 ve 5 'te verilen formüller ile sırasıly $S$ 'in varyansı ve $Z$ test istatistiği belirlenir.

$$
\begin{aligned}
& S=\sum_{i=1}^{n-1} \sum_{j=i+1}^{n} \operatorname{sign}\left(x_{j}-x_{i}\right) \\
& \operatorname{sign}\left(x_{j}-x_{i}\right)=\left\{\begin{array}{cc}
+1 & x_{j}>x_{i} \\
0 & x_{j}=x_{i} \\
-1 & x_{j}<x_{i}
\end{array}\right. \\
& \operatorname{var}(S)=\left[n(n-1)(2 n+5)-\sum_{i=1}^{m} t_{i} i(i-1)(2 i+5)\right] / 18 \\
& Z= \begin{cases}\frac{S-1}{\sqrt{\operatorname{var}(S)}} & S>0 \\
0 & S=0 \\
\frac{S+1}{\sqrt{\operatorname{var}(S)}} & S<0\end{cases}
\end{aligned}
$$

Burada, $n$ veri sayısını, $x$ ise $i$ ve $j$ zamanlarındaki veriyi, $m$ veri setindeki tekrar gözlem sayıları, $t i$ değeri $i$ uzunluğundaki bir seride tekrarlanan gözlemleri göstermektedir.

İstatistiksel olarak anlamlı bir trendin belirlenmesi için $Z$ değeri kullanılır. $\alpha$ anlamlılık düzeyinde $|Z|<Z_{\alpha / 2}$ olması durumunda anlamlı bir trend olmadığı, $|Z| \geq Z_{\alpha / 2}$ olması durumunda ise istatistiksel olarak anlamlı bir trend olduğu ve $S$ değerinin işaretine göre de trendin artan ya da azalan yönde olduğu sonucuna varılır. Örneğin, $\% 95$ güven aralığında $Z_{\alpha / 2}$ değeri normal dağılım tablolarına göre $\pm 1,96, \% 90$ güven aralığında ise $Z_{\alpha / 2}$ değeri $\pm 1,645$ olarak alınmaktadır.

\subsubsection{Spearman'ın Rho Testi (Spearman'm Rho Test)}


İki zaman serisi arasında korelâsyonu belirleme amaciyla kullanılan Spearman'ın Rho testi, trend varlığının belirlenmesi için de kullanılabilir [29]. Sıra istatistiği $R_{x i}$, verilerin küçükten büyüğe veya büyükten küçüğe doğru sıralanması ile belirlenir. Gözlem serisi $X=\left(x_{1}, x_{2}, \ldots, x_{n}\right)$ olmak üzere; bu değerler zamanla artar veya azalır. Spearman'ın Rho testi istatistiği $r_{s}$ bağıntısı ile Denklem 6'daki gibi hesaplanır:

$$
r_{s}=1-6 \frac{\left[\sum_{i=1}^{n}\left(R\left(x_{i}-i\right)^{2}\right)\right]}{\left.\left(n^{3}-n\right)\right)}
$$

$n>30$ için $r_{s}$ dağılımı normale yaklaşacağından normal dağılım tabloları kullanılır [29]. Bunun için $r_{s}$ ' nin test istatistiği olarak tanımlanan $Z$ Denklem 7'deki gibi hesaplanır:

$$
Z=r_{s} \sqrt{n-1}
$$

$|Z|$ değeri, $\alpha$ anlamlılık seviyesinde standart normal dağılım tablolarından tespit edilen $Z_{\alpha 2}$ değerinden büyük ise istatistiksel olarak anlamlı bir trend varlığının olduğu, $r_{s}$ pozitif ise artan, negatifse azalan yönde trend olduğu sonucuna varılır. Örneğin, $\% 95$ güven aralığında $Z_{\alpha / 2}$ değeri normal dağılım tablolarına göre $\pm 1.96, \% 90$ güven aralığında ise $Z_{\alpha / 2}$ değeri \pm 1.645 olarak alınmaktadır.

\subsubsection{Yenilikçi Şen Yöntemi (Innovative Şen Method)}

Şen [14] tarafından önerilen bu yöntemde, ölçümü alınan hidrolojik değişkenin veri serisi, zamansal olarak ölçüm başlangıç tarihinden son ölçüm tarihine doğru sıralanır. Sonrasında, oluşan seri ilk tarihten itibaren iki eşit parçaya bölünür ve ayrı ayrı kendi içinde küçükten büyüğe doğru sıralanır. Kartezyen koordinat sistemine göre, oluşan iki veri sütununun ilki $\left(\mathrm{X}_{\mathrm{i}}\right) \mathrm{X}$-eksenine, diğeri $\left(\mathrm{X}_{\mathrm{j}}\right)$ ise Y-eksenine yerleştirilir (Şekil 2).

Oluşan iki boyutlu grafik üzerinde veri noktaları 1:1 $\left(45^{\circ}\right)$ çizgisinin üzerine toplanmış ise bir trend yoktur, çizginin altıda ise azalan, üstünde olması durumunda ise artan bir trend vardır şeklinde yorumlanmaktadır.

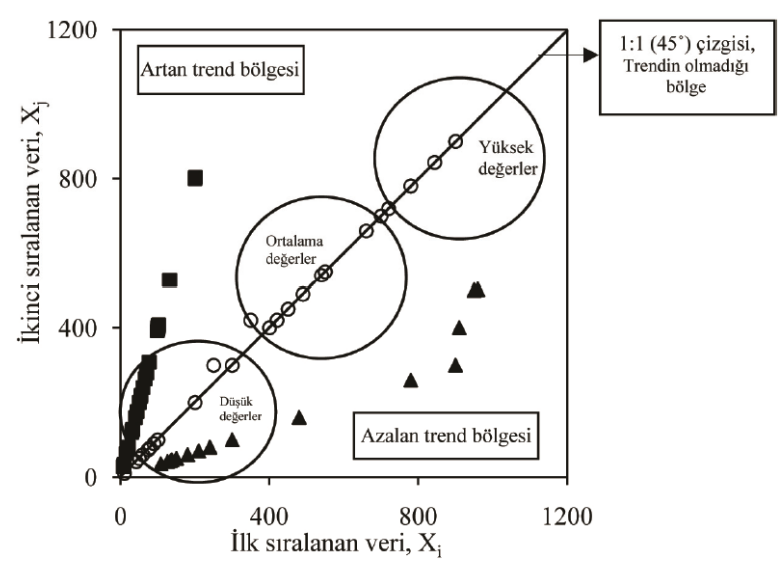

Şekil 2. Yenilikçi Şen yöntemine göre trend meydana gelme durumu

\subsubsection{Sen'in Trend Eğim Metodu}

Parametrik olmayan bir test ile zaman serisinin lineer değişimi yani eğiminin belirlenmesi amaçlanmaktadır [30]. Bu yöntemde $Q_{i}$ Denklem 8'de verilmiş olan bağıntı ile hesaplanır.

$$
Q_{i}=\left(x_{j}-x_{k}\right) /(j-k)(i=1, \ldots, N)
$$


Burada, veri sayısı $N, j$ ve $k$ zamanlarındaki veriler $x_{j}$ ve $x_{k}{ }^{\prime}$ dır. Elde edilen $Q_{i}$ değerleri küçükten büyüğe doğru sıralanır ve medyan değeri alınır. Alınan $Q_{\text {medyan }}$ ise ilgili gözlemlerin birim zamandaki değişimi olarak değerlendirilir. Hesaplanan $Q_{\text {medyan }}$ değerinin pozitif olması artan yönde, negatif olması ise azalan yönde bir trendin olduğunu gösterir.

\section{BULGULAR (RESULTS)}

\section{1. İç Bağımlılık Etkisinin Belirlenmesi (Effect of Serial Correlation)}

Şanlıurfa istasyonuna ait aylık güneşlenme şiddetine ait verilerin monotonik trendleri belirlenmeden önce literatürde önerildiği şekilde iç bağımlılık etkisinin belirlenmesi ve iç bağımlılığının etkisinin varlığı durumunda da giderilmesi gerekmektedir. Bu amaçla Salas [24] tarafindan önerilen ve yöntemlerde detayları verilen yöntem ile ilk olarak verilerin Lag-1 korelasyon katsayıları belirlenmiş ve Şekil 3'te verilmiştir. Buna göre, ele alınan tüm aylarda ve yıllık ortalama güneşlenme şiddeti değerlerinde belirlenen seri korelasyonların tamamının pozitif olduğu görülmüştür. Bunun yanında iç bağımlılık bulunan aylar ise ocak, nisan, mayıs, haziran, temmuz, ağustos, eylül, kasım ve yıllık ortalama olduğu görülmüştür. İç bağımlılık belirlenen bu zaman ölçeklerinde iç bağımlılık etkisi giderildikten sonra monotonik trendler belirlenmiştir.

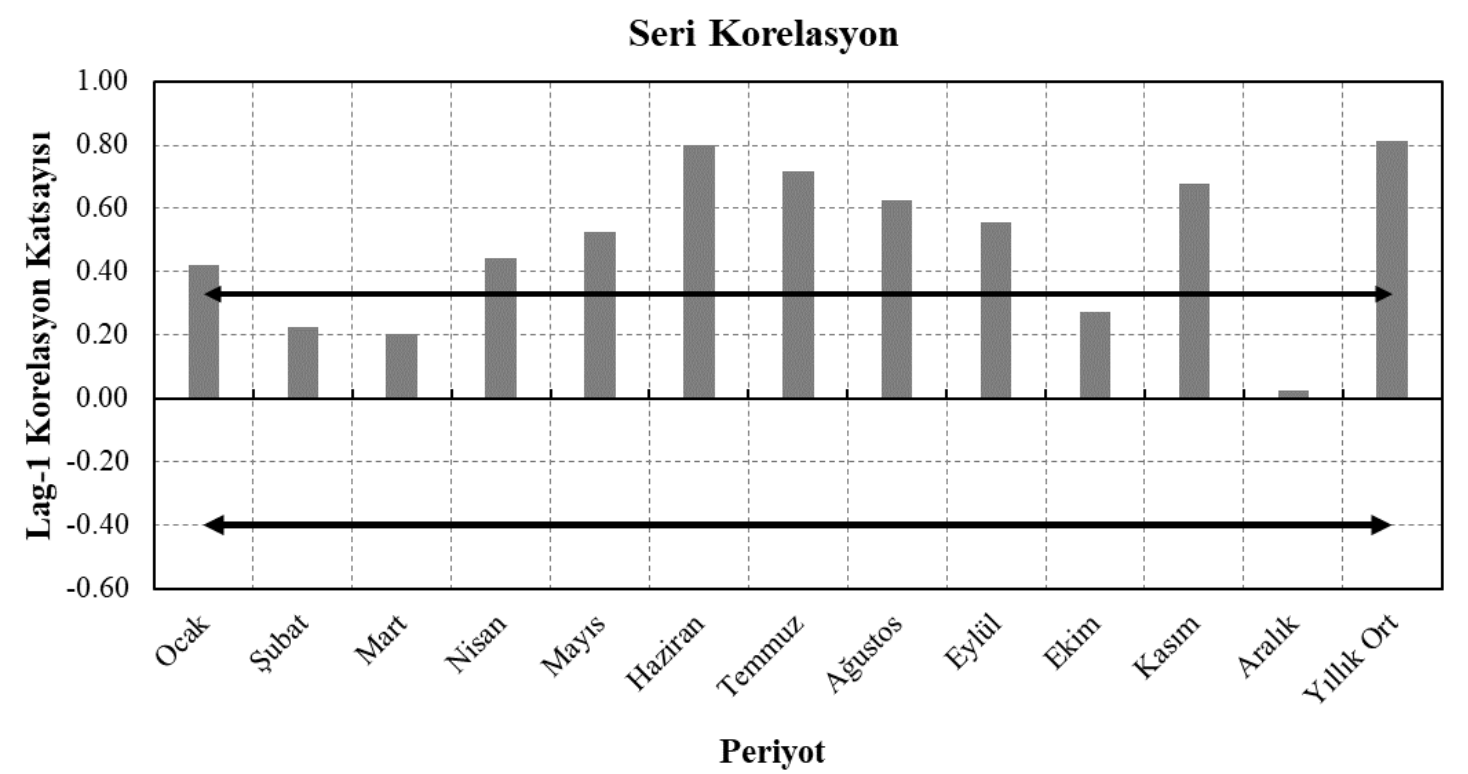

Şekil 3. Şanlıurfa istasyonuna ait belirlenen Lag-1 korelasyon katsayısının dağılımı

\subsection{Monotonik Trend Analizi Sonuçları (Results of Monotonic Trend Analysis)}

İç bağımlılık etkisi giderilmiş zaman serilerinin Mann-Kendall (MK) ve Spearman'ın Rho (SR) testlerine göre belirlenmiş $Z$ değerleri ile Sen'in trend eğim metodu ile belirlenen lineer trendler Tablo 2'de verilmiştir. Ayrıca MK ve SR testlerinde elde edilen $Z$ değerlerinin dağılımı Şekil 4'te verilmiştir. Tablo 2'e göre, sadece ekim ayında $M K$ testi ile belirlenen $Z$ değeri, Bölüm 2.2.1'de ifade edilen $Z_{\alpha / 2}$ değeri olan 1.645 'ten büyük olduğu için \%90 güven aralığında anlamlı trend oluşmaktadır. SR testi ise ekim ayının yanı sıra mart ayında da \%90 güven aralığında anlamlı trend belirlemiştir. Mart ayı dışındaki tüm sonuçlarda MK testi ile SR testlerinin birbirleri ile uyumlu sonuçlar verdiği görülmüsstür. Trend eğim değerleri incelendiğinde ele alınan tüm zaman ölçekleri için artan yönde bir eğim belirlendiği görülmüştür. Ayrıca, en yüksek artış miktarının en yüksek ortalama değere sahip olan haziran ve temmuz aylarında değil, mayıs ayında meydana geldiği görülmüştür. 
Tablo 2. Monotonik trend analizi sonuçları

\begin{tabular}{|c|c|c|c|}
\hline Aylar & MK Test & SR Test & Sen Slope \\
\hline Ocak & 0,85 & 1,07 & 0,65 \\
\hline Şubat & 0,47 & 0,50 & 0,44 \\
\hline Mart & 1,22 & $\mathbf{1 , 6 7}$ & 1,34 \\
\hline Nisan & 0,85 & 0,92 & 1,91 \\
\hline Mayıs & 1,09 & 1,21 & 3,21 \\
\hline Haziran & 0,18 & 0,09 & 2,99 \\
\hline Temmuz & 0,81 & 0,92 & 3,17 \\
\hline Ağustos & 1,52 & 1,44 & 2,02 \\
\hline Eylül & 0,14 & 0,26 & 0,99 \\
\hline Ekim & $\mathbf{1 , 7 8}$ & $\mathbf{1 , 9 0}$ & 1,20 \\
\hline Kasım & 0,53 & 0,62 & 1,40 \\
\hline Aralık & 1,33 & 1,63 & 0,77 \\
\hline Y1llk Ort. & 0,73 & 0,62 & 1,64 \\
\hline
\end{tabular}

Şekil 4'te Z değerlerinin aylara ve yıllık ortalama değerlere göre dağılımı görülmektedir. Şekilde yer alan sütunların kesikli çizgiyi geçmesi durumunda $\% 90( \pm 1,645)$, düz çizgiyi kesmesi durumunda ise $\% 95$ $( \pm 1,96)$ güven aralığında anlamlı trendin meydana geldiği anlaşılmaktadır. Burada da görüldügü gibi, sadece ekim ayında iki yönteme göre de $\% 90$ güven aralığında anlamlı trend belirlenmiş, mart ayında ise sadece SR test ile \%90 güven aralığında anlamlı trend varlığı belirlenmiştir.

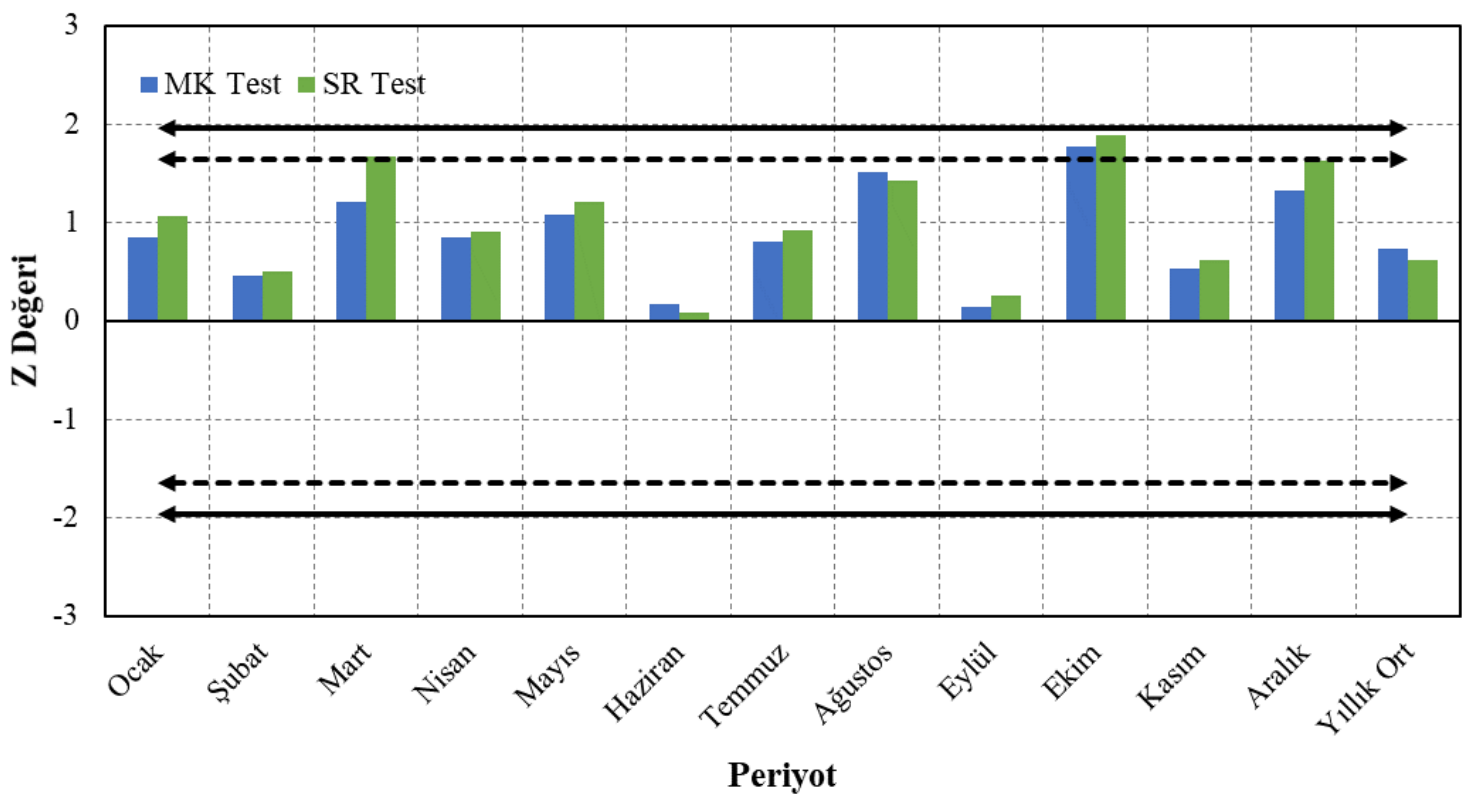

Şekil 4. MK ve SR yöntemleri ile belirlenen $Z$ değerlerinin dağılımı

\subsection{Yenilikçi Şen Yöntemi Sonuçları (Results of Innovative Şen Method)}

Şanlıurfa istasyonuna ait güneşlenme şiddeti değerleri Yenilikçi Şen Yöntemi ile trendlerinin belirlenmesinde iki değerlendirme yapılmıştır. Bunlardan birincisi tüm veriler beraber kullanılarak bir çalışma yapılmış ve tüm değerler üzerinden trend değerlendirmesi yapılmıştır. İlk yaklaşım olarak değerlendirilen tüm verilerin zamansal dağılımları ve Yenilikçi Şen Yöntemine göre sıralanmış verilerin saçılım grafiği Şekil 5'te verilmiştir. Verilerin zamansal dağılımı incelendiğinde, ölçümün yapılmaya başladığı 1982-1989 yıllarında maksimum değerlerin sonraki yıllardaki maksimum değerlerden küçük olduğu sonrasında ise verilerinin dağılımının genel olarak birbirlerine benzer olduğu görülmektedir. Şeklin sağ tarafında bulunan Yenilikçi Şen Yöntemine göre yapılan analiz sonucunda ise verilerinin neredeyse tamamının az da olsa bir artış trendinde olduğu ( $45^{\circ}$ çizgisinin üst tarafında yer almaktadır) anlaşılmaktadır. 
Böylece güneşlenme şiddeti değerlerinin genel olarak artma trendinde olduğunu söylemek mümkün olmaktadir.
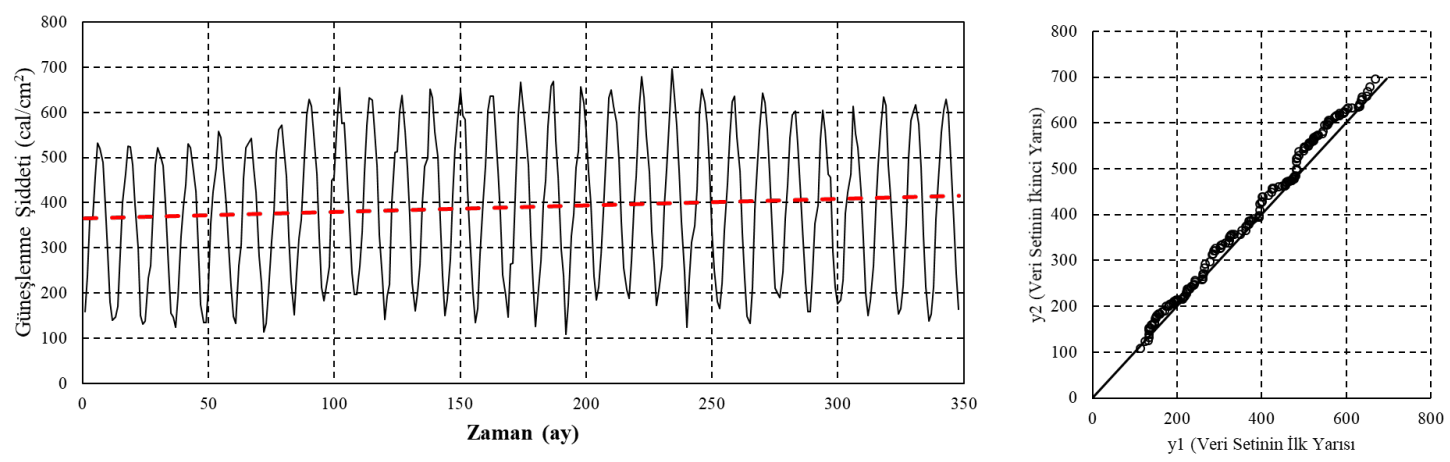

Şekil 5. Yenilikçi Şen Yöntemine göre tüm verilerin trend analizi

Aylık ve yıllık ortalama değerlerin ayrı ayrı değerlendirilmesi ile ilgili Yenilikçi Şen Yöntemine göre elde edilen sonuçlar Şekil 6'da verilmiştir. Buna göre neredeyse tüm aylarda düşük güneşlenme şiddeti değerlerinin açık bir şekilde artma trendinde olduğu görülmektedir. Yüksek değerlerde ise mart, nisan ve eylül aylarında bir azalmanın olduğu, haziran, temmuz, ağustos ve kasım aylarında ise artma olduğu, diğer aylarda ise herhangi anlamlı bir fark olmadığ 1 anlaşılmaktadır. Yıllık ortalama değerlerin de aylardaki genel yapıya benzer olduğu, yani, düşük değerlerde açık bir şekilde değerlerin artma trendine sahip olduğu, ancak yüksek değerlerde anlamlı bir artma ya da azalma meydana gelmediği açık bir şekilde görülmektedir.

\section{SONUÇLAR (CONCLUSIONS)}

Bu çalışmada, Türkiye'nin tarımsal sulama bağlamından en önemli illerden biri olan ve tarımsal sulamalar için oldukça önemli bir enerji harcanan Şanlıurfa iline ait güneşlenme şiddetinin zamansal trendleri belirlenmiştir. Parametrik olmayan Mann-Kendall ve Spearman'ın Rho testleri ile, sonuçları grafiksel olarak veren Yenilikçi Şen Yöntemi ile yapılan analizler sonucunda elde edilen sonuçlar aşağıda özetlenmiştir.

- Veri setlerinin iç bağımlılıkları kontrol edilmiş ve neredeyse tüm aylarda bir iç bağımlılık belirlenmiş ve bu iç bağımlılık etkisi pre-whitening yöntemi ile giderilmiştir.

- Mann-Kendall testi ile sadece ekim ayında \%90 güven aralığında anlamlı trend belirlenirken, Spearman'ın Rho testi ile \%90 güven aralığında ekim ayının yanı sıra mart ayında da \%90 artan yönde anlamlı trend belirlemiştir.

- Sen'in trend eğim metodu ile trend eğimleri belirlenmiş ve ele alınan tüm zaman ölçeklerinde artan yönde bir eğim oluğu ve en yüksek artış miktarının en yüksek ortalama değere sahip olan haziran ve temmuz aylarında değil, mayıs ayında meydana geldiği görülmüştür.

- Tüm veriler kullanılarak Yenilikçi Şen Yöntemi ile yapılan analiz sonucunda, verilerinin neredeyse tamamının az da olsa bir artış trendi olduğu belirlenmiştir.

- Yenilikçi Şen yöntemi ile aylık değerlerin değerlendirilmesinde ise neredeyse tüm aylarda düşük güneşlenme şiddeti değerlerinin açık bir şekilde artma trendinde olduğu görülmüştür. Yüksek değerlerde ise mart, nisan ve eylül aylarında bir azalmanın olduğu, haziran, temmuz, ağustos ve kasım aylarında ise artma olduğu, diğer aylarda ise herhangi anlamlı bir fark olmadığı anlaşılmıştır.

Yapılan analizler neticesinde, özellikle Yenilikçi Şen Yönteminin verilerin analizinde geleneksel olarak kullanılan monotonik trend analizi yöntemlerine göre uygulayıcılar açısından daha detaylı sonuçlar vermesinin ve zaman serisinin küçük, büyük ve orta değerlerinde oluşan trend sonuçları yorumlama açısından kullanışlı olduğu görülmüştür. Bunun yanında analizi yapılan istasyonun bulunduğu bölgede diğer istasyonların da dahil edilerek mekansal bir trend analizi çalışması yapılmasının uygun olacağı değerlendirilmektedir. 


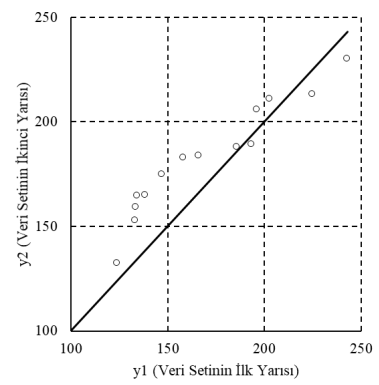

(a) Ocak

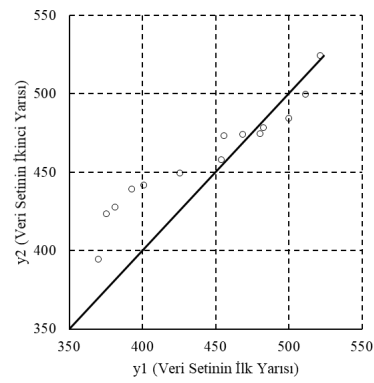

(d) Nisan

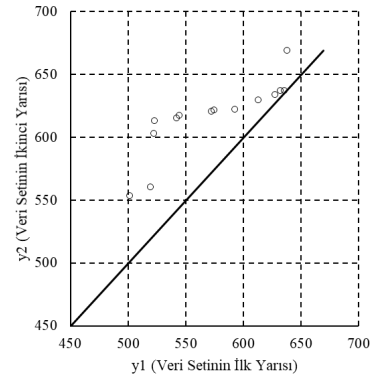

(g) Temmuz

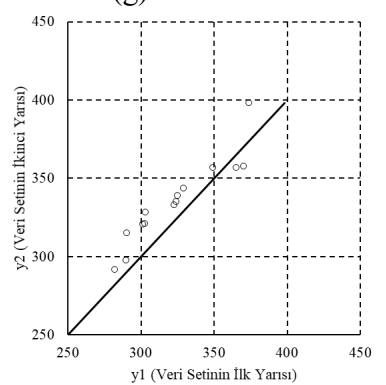

(j) Ekim

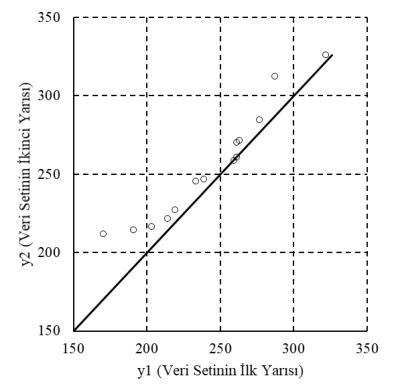

(b) Şubat

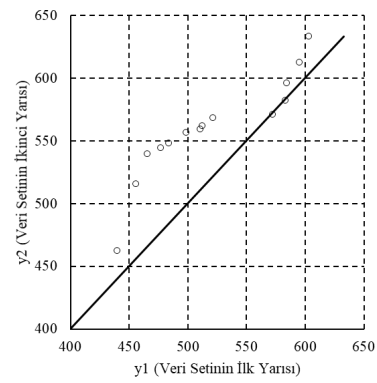

(e) Mayıs

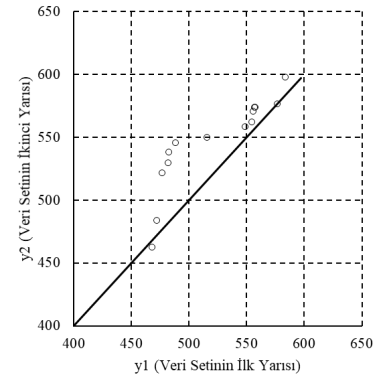

(h) Ağustos

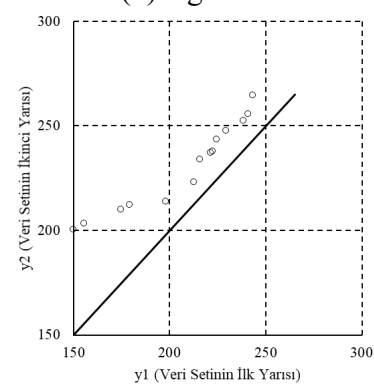

(k) Kasim

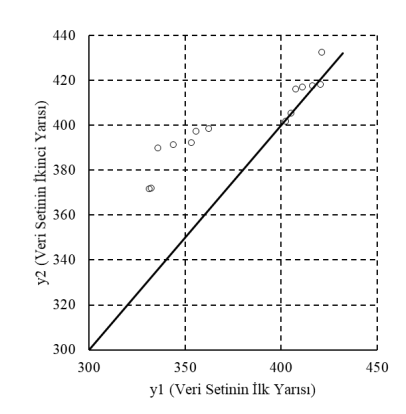

(m) Yillık Ortalama

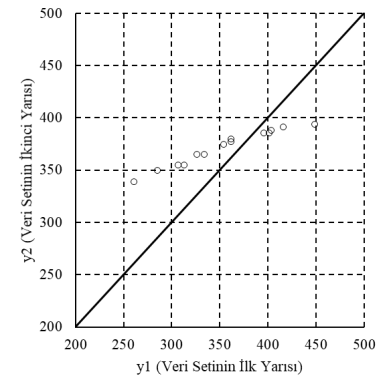

(c) Mart

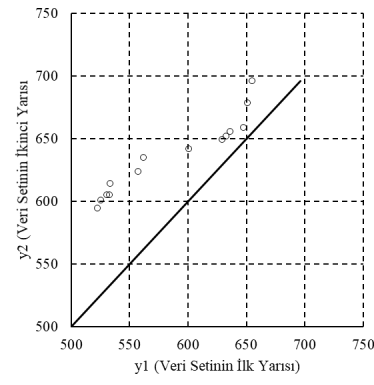

(f) Haziran

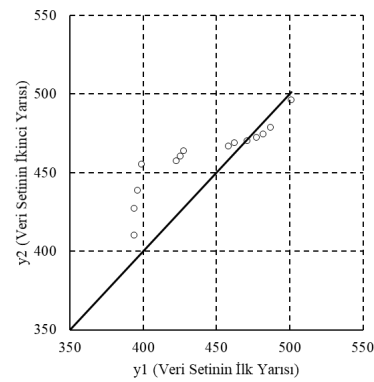

(i) Eylül

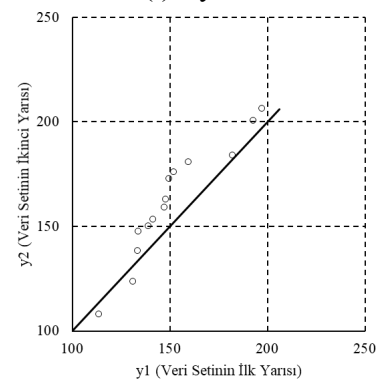

(1) Aralık

Şekil 6. Yenilikçi Şen Yöntemine göre aylık güneşlenme şiddeti değerlerinin trend analizi 


\section{TEŞEKKÜR (ACKNOWLEDGMENTS)}

Bu çalışmada kullanılan güneşlenme şiddeti verilerini sağlayan Meteoroloji Genel Müdürlüğü’ne (MGM) teşekkür ederiz.

\section{ÇIKAR ÇATIŞMASI (CONFLICT OF INTEREST)}

Makale yazarları aralarında herhangi bir çıkar çatışması olmadığını beyan ederler.

\section{KAYNAKLAR (REFERENCES)}

[1] C. Beer, M. Reichstein, E. Tomelleri, P. Ciais, M. Jung, N.C. Carvalhais, Rodenbeck, M.A. Arain, D. Baldocchi, G.B. Bonan, Terrestrial gross carbon dioxide uptake: global distribution and covariation with climate. Science, 329 (2010) 834-838.

[2] M. D. Islam, I. Kubo, M. Ohadi, A. A. Alili, Measurement of solar energy radiation in Abu Dhabi, UAE. Applied Energy, 86 (2009) 511-515.

[3] T. Khatib, A. Mohamed, K. Sopian, A review of solar energy modeling techniques. Renewable and Sustainable Energy Reviews, 16 (2012) 2864-2869.

[4] H. C. Power, Trends in solar radiation over Germany and an assessment of the role of aerosols and sunshine duration. Theoretical and Applied Climatology, 76 (2003) 47-63.

[5] V. Russak, Changes in solar radiation and their influence on temperature trend in Estonia. Journal of Geophysical Research: Atmospheres, 308 (2009) 49-50.

[6] V. Silva, R. A. Silva, E. P. Cavalcanti, C. C. Braga, P. V. Azevedo, V. P. Singh, E. R. Pereira, Trends in solar radiation in NCEP/NCAR database and measurements in northeastern Brazil. Solar Energy, 84 (2010) 1852-1862.

[7] S. T. Turnock, D. V. Spracklen, K. S. Carslaw, G. W. Mann, M. T. Woodhouse, P. M. Forster, J. Haywood, C. E. Johnson, M. Dalvi, N. Bellouin, Modelled and observed changes in aerosols and surface solar radiation over Europe between 1960 and 2009. Atmospheric Chemistry and Physics, 15 (2015) 13457-13513.

[8] T. Caloiero, R. Coscarelli, E. Ferrari, M. Mancini, Trend detection of annual and seasonal rainfall in Calabria (Southern Italy), International Journal of Climatology, 31 (2011) 44-56.

[9] H. Tabari, S. Marofi, M. Ahmadi, Long-term variations of water quality parameters in the Maroon River, Iran. Environmental Monitoring and Assessment, 177 (2011) 273-287.

[10] R. K. Chowdhury, S. Beecham, J. Boland, J Piantadosi, Understanding South Australian rainfall trends and step changes. International Journal of Climatology, 35 (2015) 348-360.

[11] E. Eris, and N. Agiralioglu, Homogeneity and trend analysis of hydrometeorological data of the Eastern Black Sea Region. Turkey. Journal of Water Resource and Protection, 4 (2012) 92-105.

[12] K. Yenigün, V. Gümüş, H. Bulut, Trends in streamflow of the Euphrates basin, Turkey. In: Proceedings of the Institution of Civil Engineers-Water Management. 161:4 (2008) 189-198.

[13] V. Gumus, Spatio-temporal precipitation and temperature trend analysis of the Seyhan-Ceyhan River Basins, Turkey. Meteorological Applications, 26:3 (2019) 369-384.

[14] Z. Şen, Innovative trend analysis methodology. Journal of Hydrologic Engineering. 17 (2012) 10421046. 
[15] M. Ay, O. Kisi, Investigation of trend analysis of monthly total precipitation by an innovative method. Theoretical and Applied Climatology, 120 (2015) 617-629.

[16] O. Kisi, An innovative method for trend analysis of monthly pan evaporations. Journal of Hydrology, 527 (2015) 1123-1129.

[17] $\mathrm{H} . \mathrm{Wu}, \mathrm{H}$. Qian, Innovative trend analysis of annual and seasonal rainfall and extreme values in Shaanxi, China, since the 1950s. International Journal of Climatology, 37:5 (2017) 2582-2592.

[18] C. Liu, X. Liu, H. Zheng, Z. Yan, Change of the solar radiation and its causes in the Haihe River Basin and surrounding areas. Journal of Geographical Sciences, 20 (2010) 569-580.

[19] B. Aksoy, Solar radiation over Turkey and its analysis. International Journal of Remote Sensing, 32:21 (2011) 6261-6272.

[20] Z. Zhou, L. Wang, A. Lin, M. Zhang, Z. Niu, Innovative trend analysis of solar radiation in China during 1962-2015. Renewable energy, 119 (2018) 675-689.

[21] GEPA. 2020. https://gepa.enerji.gov.tr/MyCalculator/, son erişim tarihi: 12.11.2020.

[22] D. R. Helsel, R. M. Hirsch, Statistical methods in water resources. Vol. 49. Elsevier, 1992.

[23] H. Von Storch, A. Navarra, Applications of Statistical Techniques, 1995.

[24] J. D. Salas, Applied modeling of hydrologic time series. Water Resources Publication, 1980.

[25] T. Mohsin, W. A. Gough, Trend analysis of long-term temperature time series in the Greater Toronto Area (GTA). Theoretical and Applied Climatology, 101:3-4 (2010) 311-327.

[26] M. Gocic, S. Trajkovic, Analysis of precipitation and drought data in Serbia over the period 19802010. Journal of Hydrology, 494 (2013), 32-42.

[27] H. B. Mann, Nonparametric tests against trend. Econometrica, 13 (1945), 245-259.

[28] M. G. Kendall, Rank correlation methods. 1948.

[29] S. Yue, C. Y. Wang, Applicability of pre-whitening to eliminate the influence of serial correlation on the Mann-Kendall test. Water Resources Research, 38:6 (2002), 1-4.

[30] P. K. Sen, Estimates of the regression coefficient based on Kendall's tau. Journal of the American statistical association, 63:324 (1968), 1379-1389. 